\title{
FUNÇÃO SOCIAL E RESPONSABILIDADE SOCIAL EMPRESARIAL: O PRINCÍPIO DA SOLIDARIEDADE COMO MARCO JURÍDICO- CONSTITUCIONAL PARA UMA NOVA EMPRESA CIDADÃ
}

\author{
Joana D’Arc Dias Martins
}

\begin{abstract}
RESUMO: O artigo busca analisar o que seria a função social da empresa e a importância das ações de responsabilidade social. A empresa contemporânea assumiu novos papeis perante o Estado deixando de perseguir apenas lucro. Dado a sua relevância e transformações sociais que ela é capaz de operar na sociedade, tratar-se-á sobre a atuação do Estado e o uso de incentivos fiscais como mecanismo de indução às condutas socialmente responsáveis, sobremodo aquelas que contribuem para a promoção da dignidade da pessoa humana. Trata-se de pesquisa bibliográfica e o método utilizado foi o dedutivo, por se tratar de abordagem teórica e conceitual-normativa.
\end{abstract}

Palavras-chave: Função social; responsabilidade social; globalização; incentivos fiscais; desenvolvimento sustentável.

\section{FROM SOCIAL FUNCTION TO BUSINESS SOCIAL RESPONSIBILITY: THE PRINCIPLE OF SOLIDARITY AS A LEGAL-CONSTITUTIONAL FRAMEWORK FOR A NEW CITIZEN COMPANY}

\begin{abstract}
The article seeks to analyze what would be the company's social function and importance of social responsibility actions. Contemporary company took on new roles before the State, ceasing to pursue only profit. Given its relevance and social transformations that it is capable of operating in society, it will deal with the performance of the State and the use of tax incentives as a mechanism to induce socially responsible behavior, especially those that contribute to the promotion of dignity of the human person. Is a bibliographic research and the method used was the deductive one, as is a theoretical conceptual-normative approach.
\end{abstract}

Keywords: Social function; social responsibility; globalization; . tax breaks; sustainable development

\section{INTRODUÇÃO}

O Estado Democrático de Direito, modelo implantado no Brasil a partir da $\mathrm{CF} / 88$, buscou harmonizar concepções oriundas dos Estados Liberal e Social, e ao dispor acerca do direito à propriedade privada, inclusive reconhecendo-o como um direito fundamental,

\footnotetext{
* Doutoranda e mestre em Direito pela Universidade de Marília - UNIMAR - Marília - São Paulo (Brasil). Promotora de Justiça do Estado do Acre. E-mail: joanamartins.ac@gmail.com.
} 
condicionou-a ao atribuir-lhe uma função social a cumprir. Dessa feita, o sentido de propriedade, compreendido ao longo dos séculos como direito puramente individual e protegido de qualquer ingerência de particulares e mesmo do Estado, passou a sofrer limitações.

E é nessa conjuntura que surge o conceito de função social da propriedade, nascido da necessidade do Estado moderno limitar o individualismo em prol de valores maiores, ligados à exigência social de garantir o interesse da coletividade.

Nesse estudo será analisado como as ações de responsabilidade social empresarial configuram diferenciais competitivos, visto que os consumidores, mais conscientes do seu papel, passaram a atribuir um importante valor aos produtos e serviços de empresas que apoiam causas social ou ambiental. Por outro lado, ao atribuir às empresas obrigações ligadas ao cumprimento de funções outras que não a obtenção de lucro, o Estado transfere à iniciativa privada papeis fundamentais que lhe competiam, entre elas a promoção da justiça social. Nesse contexto, importante analisar quais os instrumentos a serem utilizados pelo Poder Público como forma de incentivar essa atuação socialmente responsável em prol da sociedade.

Por fim, a pesquisa se justifica principalmente pela atualidade e a relevância do tema. O método de abordagem é dedutivo e a técnica de pesquisa será bibliográfica e documental. O artigo está dividido em seis tópicos que seguem os objetivos específicos do trabalho

\section{Evolução do conceito de função social da propriedade}

A alteração do paradigma do Estado Liberal, caracterizado pela fruição absoluta de direitos subjetivos e pelo receio de intervenção estatal nas relações privadas, para o Estado Social, ocorreu em razão da superação da ideia de direitos subjetivos e liberdades como poderes absolutos, vistos sob uma perspectiva individualista e formalista.

As experiências do Estado Liberal demonstraram que o mero reconhecimento das liberdades formais não seria suficiente para assegurar que as pessoas realizem os seus projetos de vida, pois estes dependem de certa quantidade de recursos materiais sem os quais a liberdade cai no vazio (FRAZÃO, 2011, p 185). Por conseguinte, não pode haver autonomia sem que se encontre uma forma de compensar as desigualdades inaceitáveis por meio de um critério de justiça distributiva, tal como a dimensão ativa da função social dos direitos pretende concretizar. 
Logo, o Estado Social, ao harmonizar o capitalismo com o bem-estar social, dando início ao processo de superação da dicotomia entre direito público e privado, passou a ser compreendido no contexto de uma relação de recíproca complementariedade e dependência, tornando-se o direito privado um instrumento de justiça social.

Destarte, no intuito de reparar falhas do sistema de livre mercado e de compensar desigualdades econômicas, surgiram diversas teorias favoráveis à intervenção do Estado na economia, de maneira a conciliar a liberdade de iniciativa e a propriedade privada, de um lado, e os interesses sociais, de outro. Nesse sentido, desempenhou fundamental importância o pensamento de John Maynard Keynes, que forneceu modelo capaz de estabelecer correspondência global entre os imperativos de crescimento econômico e as demandas sociais no âmbito de um Estado econômica e socialmente ativo.

Os primeiros delineamentos sobre a função social da propriedade advêm do pensamento de Auguste Comte, que procurou substituir o caráter pessoal e arbitrário da propriedade privada por finalidade orientada para o bem da sociedade, o que posteriormente ainda foi desenvolvido pela sociologia e pela doutrina social da Igreja Católica.

Perfilhando esse mesmo entendimento, Léon Duguit (1975, p. 179) defendeu a concepção de função social da propriedade, sob a assertiva de que o homem deveria cumprir sua parcela de obrigação junto à comunidade, pois ele vive em sociedade e a sociedade subsiste apenas pela solidariedade que une os indivíduos que a compõe. Segundo o autor, a propriedade não teria uma função, ela seria a própria função social, ou seja, uma propriedadefunção, refutando de forma veemente a concepção de direito subjetivo, razão pela qual foi considerado extremista.

Certo é que, posteriormente, a ideia de função social avançou e projetou-se sobre outros direitos e, inclusive, sobre a liberdade de contratar, suscitando discussões sobre a boafé, o equilíbrio contratual e a justiça material.

O Brasil, por sua vez, seguindo a tendência mundial de adoção de Constituições sociais, aprovou em 1934 a primeira Constituição Social ou Econômica, condicionando o exercício da propriedade ao interesse social. Essa mesma orientação manteve-se na Constituição de 1946, porém, somente restou evidenciada de forma explícita na Constituição de 1967, que tinha como escopo a justiça social consubstanciada na função social.

Mas é na Constituição Federal de 1988 que a função social da propriedade atinge seu apogeu. Ela expressamente elegeu a propriedade e sua função social como princípios 
norteadores da ordem econômica (artigo 170, incisos II e III). Ademais, no artigo $5^{\circ}$ (incisos XXII, XXIII), a propriedade é apontada como um direito fundamental. Logo, conclui-se que, ao condicionar a propriedade à sua função social e submetê-la à existência digna e à justiça social, o legislador constituinte relativizou o conceito de propriedade.

O Código Civil de 2002, seguindo os novos paradigmas dispostos na Constituição de 1988, previu o artigo 421, dispondo sobre a função social do contrato. Essa inequívoca tendência à despatrimonialização do direito civil levou ao entendimento de que o contrato não poderia ser visto apenas como um veiculador da vontade dos contratantes, e sim um instrumento de convívio social e de preservação dos interesses da coletividade. Esse abrandamento das regras dos contratos, que outrora era tido como expressão da liberdade de contratar em sua feição individual, passou a ser reconhecido como de interesse de todos e deveria cumprir uma finalidade social. Com a função social do contrato, o direito público e o direito privado são harmonizados pela Constituição Federal. (PETTER, 2005, p. 220).

\section{A função social da empresa no contexto do estado democrático de direito}

Modernamente não se admite mais a empresa individualista, cuja única finalidade seja voltada à geração de lucros para seus sócios. A importância desse ente é tão grande que transcende o interesse exclusivo dos sócios. Ela é uma expressão social, econômica e financeira, capaz de influenciar toda uma comunidade, razão pela qual boa parte da doutrina, sobremodo os cultores do Direito Econômico a compreendem como um ente personificado.

Dessa forma, a autonomia do empresário não é um completo exercício do livre arbítrio. Ao contrário. Os atos empresariais não devem apenas evitar fins antissociais, mas, além disso, devem estar em conformidade com a razão pela qual a livre iniciativa foi garantida e reconhecida constitucionalmente: busca da dignidade e da justiça social.

A função social da empresa, enquanto instrumento para uma sociedade mais solidária, não representa uma simples regra. Qualifica-se como princípio da ordem econômica constitucional, além de ser um vetor para o exercício da atividade econômica, traçando uma linha de ajuste entre a liberdade da iniciativa privada e a subordinação ao interesse coletivo.

Por conseguinte, pode-se afirmar que uma empresa cumpre sua função social quando atende aos interesses da coletividade, produzindo bens e serviços que sejam compatíveis com os anseios da comunidade. Assim, uma empresa que gera emprego, renda e produz 
mercadorias úteis à sociedade estaria cumprindo sua função social. Nesse sentido, colacionase o entendimento da Ministra Nancy Andrighi, no Agravo Regimental no 110.250 - DF, que diz:

A função social da empresa exige sua preservação, mas não a todo custo. A sociedade empresária deve demonstrar ter meios de cumprir eficazmente tal função, gerando empregos, honrando seus compromissos e colaborando com o desenvolvimento da economia, tudo nos termos do art. 47 da Lei $n^{\circ}$ $11.101 / 05$.

No contexto da CF/88, o artigo 170 tratou da Ordem Econômica e Financeira, prevendo diversos princípios que orientam e direcionam o exercício da livre iniciativa empresarial. E a função social da propriedade, dado sua relevância, mantém relação direta com esses princípios, procurando destacar que o fim da empresa, além do óbvio objetivo de proporcionar benefícios a todos os envolvidos diretamente com a atividade empresarial, seria também propiciar benefícios concretos à coletividade. Não é por outro motivo que há considerável ação do legislador nos assuntos descritos pelo aludido artigo com vistas a concretizar tais princípios em regulação jurídica específica.

Enfim, segundo os defensores desse princípio, a empresa não deve atender apenas os interesses egoísticos do empresário individual ou dos sócios da sociedade empresária, mas também os interesses difusos e coletivos de todos aqueles que são afetados pelo seu exercício.

Não obstante a questão é complexa e não encontra unanimidade junto à doutrina, visto que a expressão função social é muito vaga e de difícil compreensão, surgindo daí várias indagações e interpretações, principalmente porque o texto constitucional não definiu expressamente o que seria a função social da empresa.

Fabio Konder Comparato (1996, p. 44), por exemplo, não ratifica na íntegra o conceito de função social da empresa, afirmando tratar-se de conceito limitado para não dizer nulo. Incisivamente o autor questiona quais seriam os verdadeiros deveres da empresa, concluindo, inclusive, que somente as grandes empresas teriam condições de arcar com custos destinados ao atendimento da função social e que o objetivo da empresa não é a realização da justiça social, mas a produção de lucros.

Comparato alerta também para o fato de que a função social da empresa apresenta o risco de servir como: "disfarce retórico para o abandono, pelo Estado, de toda Política Social". Ademais, salienta que a Constituição, ao definir como objetivo fundamental da República construir uma sociedade livre, justa e solidária (art. $3^{\circ}$, I), e ao declarar que a ordem 
social tem por objetivo a realização do bem-estar e da justiça social (art. 193), ela não está autorizando a demissão do Estado. Ao contrário, o Estado continua sendo o órgão encarregado de guiar e dirigir a nação em busca de tais finalidades. (COMPARATO, 1996, p. 46)

Milton Friedman, um dos principais defensores do liberalismo da era contemporânea, aponta o mercado como sendo o meio eficaz para se alcançar os melhores resultados para a sociedade. Para ele, "um problema político, como o da liberdade individual, não está dissociado da organização econômica e se ajusta somente a um sistema de economia de mercado". (FRIEDMAN, 1984, p. 15)

Ainda, nas lições do apontado autor (FRIEDMAN, 1984, p. 13), o papel do capitalismo competitivo seria organizar a atividade econômica por meio da empresa privada e promover um mercado livre, enaltecendo o laissez-faire, de forma a reduzir o papel do Estado nos assuntos econômicos. E qualquer ação que desvirtue os objetivos econômicos é maléfica para a sociedade e seria causa de ineficiência econômica, visto que a responsabilidade social das empresas seria apenas gerar lucros.

Todavia, a despeito de respeitáveis opiniões contrárias ao exercício de funções outras que aquelas previstas no contrato social da empresa, a doutrina majoritária da atualidade e os tribunais superiores têm entendimento diverso, sob a assertiva de que o princípio da função social é impositivo e legitima a propriedade. Ademais, é inequívoco o novo papel que a empresa, sobremodo com o advento da Constituição Federal de 1988, assumiu ao lado do Estado. A empresa contemporânea, reconhecendo sua importância no contexto social, passou a buscar não apenas o lucro dos seus sócios, mas também propiciar ganhos à toda sociedade, o que por via reflexa acaba revertendo em benefícios para o próprio empreendimento. Nesse sentido os ensinamentos de Frazão:

Especialmente em um país como o Brasil, onde a pobreza e a miséria impedem parte substancial da sociedade de ter o legítimo direito à autonomia, a função social da empresa implica necessariamente a existência de um padrão mínimo de distribuição de riqueza e dos benefícios da atividade econômica, aspectos que vem sendo reconhecido pela doutrina e também pela jurisprudência. (2011, p. 201)

Por fim, todas as empresas, independentemente do seu tamanho e projeção financeira que ostenta, guarda em si um papel de estrema relevância junto à sociedade na qual se 
encontram inseridas, constituindo um decisivo instrumento no exercício das políticas econômicas, e como tal, podem realizar função social e contribuir para o desenvolvimento econômico, social e ambiental do país, além de auxiliar o pleno emprego.

Porém, ainda que pareça paradoxal, não se pode exigir que a empresa, sob o argumento de que tem uma função social a cumprir, ignore seu objetivo primeiro que é a obtenção de lucro e busca pela preservação e manutenção da atividade empresarial, até porque esse é um pressuposto para o atendimento de todos os demais interesses que se projetam sobre a empresa. Todavia, a busca pelo lucro não se contrapõe ao cumprimento de sua função social, e até mesmo ações de reponsabilidade social, como exemplo podemos citar aquelas praticadas pelo ganhador do prêmio Nobel da paz de 2006, Muhammad Yunus (2008), conhecido como "o banqueiro dos pobres", que faz pequenos empréstimos sem exigir garantia, ajudando a população mais pobre a sair da miséria, e mesmo assim obtém lucros consideráveis e menos de dois por cento das pessoas beneficiadas não conseguem saldar suas dívidas.

Portanto, extreme de dúvidas que essas novas atribuições da empresa não eliminam aquelas atribuídas precipuamente ao Estado, sobremodo a sua obrigação de dirigir a nação ao bem-estar e a justiça social, conforme preconizado no texto constitucional. Isso porque, a despeito da indispensável e valiosa colaboração da empresa, este não se exime de sua função.

\section{Da função social à responsabilidade social empresarial}

A responsabilidade social empresarial (RSE) não pode ser vista simplesmente como função social da empresa, ou seja, uma obrigação prevista em lei. Tampouco deve ser confundida como uma resposta para a sociedade ou ações de filantropia. A responsabilidade social deve ser encarada como uma obrigação que as organizações assumem, através da busca por metas que, a médio e longo prazo, sejam boas para a empresa e para a comunidade na qual está envolvida.

Conforme bem definido por Luiz Fernando Fortes Felix (2003, p. 19), a RSE diferencia-se da função social na medida em que pressupõe a voluntariedade, ou seja, o fazer além dos comandos normativos. Logo, ser socialmente responsável significa que as empresas, por meio de seus trabalhadores e de todos os seus interlocutores, vão além de suas obrigações 
em relação ao seu capital humano, ao meio ambiente e à comunidade por perceberem que o bem-estar deles reflete em seu bem-estar.

O Instituto Ethos apresenta a responsabilidade social da empresa como sendo:

\begin{abstract}
A forma de gestão que se define pela relação ética e transparente da empresa, com todos os públicos com os quais ela se relaciona e pelo estabelecimento de metas empresariais compatíveis com o desenvolvimento sustentável da sociedade, preservando recursos ambientais e culturais para as gerações, respeitando a diversidade e promovendo a redução das desigualdades sociais. (ETHOS, 2003)
\end{abstract}

Considerando o conceito trazido pelo Instituto Ethos, pode-se afirmar que ações de RSE é a performance ética esperada de uma comunidade ou de uma organização empresarial que, juntamente com o Estado, busca concretizar o desenvolvimento nacional sustentável, no âmbito econômico, social e ambiental, seguindo os ditames dos valores consagrados constitucionalmente com o objetivo de promover a dignidade da pessoa humana.

Por conseguinte, pode-se afirmar que uma empresa é socialmente responsável quando, além de cumprir sua função social, incorpora em sua atuação comportamentos que proporcionam benefícios concretos para a sociedade, por mera liberalidade e de forma perene, sem imposição coercitiva, com o claro objetivo de promover a valorização da dignidade da pessoa humana, comprometendo-se com a eficácia da aplicação dos recursos de ordem financeira e/ou material, bem como com os resultados sociais que pretende atingir. É o que a autora Linda Starke (1999, p. 09), orientada pelo modelo empresarial criado por Reidenbach e Robin ${ }^{1}$, identifica como "corporação ética".

Maria Helena Diniz (2009, p. 33), ao dissertar sobre a ética empresarial, assinala que a empresa tem responsabilidade social e desempenha uma importante função junto à comunidade, e como tal, é elemento de paz social e solidariedade, constituindo um instrumento de promoção de justiça social. Ademais, sua atuação socialmente responsável, a impulsiona a propiciar comunicação mais aberta com seus colaboradores e com a comunidade, angariando o seu respeito e garantindo sua sobrevivência no mercado globalizado.

Entre os indicadores de responsabilidade social da empresa, segundo Fernando Guilherme Tenório (TENÓRIO, 2006, p. 37), destaca-se o balanço social, que "é um instrumento de informação da empresa para a sociedade, por meio do qual a justificativa para

\footnotetext{
${ }^{1}$ Economistas responsáveis pelo principal modelo de desenvolvimento moral das corporações.
} 
sua existência deve ser explicitada"; e as certificações, que tem por objetivo "padronizar um conjunto mínimo de indicadores referentes aos aspectos éticos e de responsabilidade social na condução dos negócios”. (TENÓRIO, 2006, p. 42).

O balanço social é uma ferramenta de planejamento empresarial, capaz de mostrar com clareza informações socioeconômicas e financeiras acerca da atuação de cada empresa no meio social. Ele serve como complemento às informações tratadas pelos demonstrativos financeiros tradicionais e tem como objetivo primordial levar ao conhecimento da sociedade a atuação socialmente responsável da empresa, uma vez que as ações desenvolvidas em prol da melhoria da sociedade e do meio ambiente ajudam instigar a valorização da cidadania corporativa acarretando no estreitamento da relação da empresa/sociedade.

Por fim, percebe-se que a ideia de responsabilidade social passeia em todo o texto constitucional, como um valor implícito, devendo o intérprete, por conseguinte, usar da hermenêutica para a devida aplicação a cada caso concreto.

\section{Ações de responsabilidade social voltadas para a sustentabilidade ambiental}

A questão ambiental, a partir do momento em que se constatou que o aumento exponencial da degradação ao meio ambiente ameaçava não apenas a natureza, e o bem-estar social que dela advinha, mas também a própria existência da vida no planeta, passou a ganhar relevância e estabeleceu a necessidade de repensar as condutas humanas, levando à construção de uma racionalidade ambiental que objetivasse uma sustentabilidade de caráter prospectivo, valorizando e respeitando o equilíbrio como requisito sine qua non para a manutenção da vida e bem estar da humanidade.

E a Empresa contemporânea, diante dos novos papeis assumidos no contexto da Constituição Federal de 1988, passou a ter o compromisso ético de não sacrificar o meio ambiente em favor do lucro rápido e fácil.

Em outras tintas, a Constituição de 1988, além de dispor que a função social da empresa é norteada pela proteção ambiental, visto que a defesa do meio ambiente é fundamental à atividade empresarial na ordem econômica e social, dado sua relevância, em capítulo próprio tratou do meio ambiente e da sustentabilidade (art. 225), definindo-a como o compromisso ético firmado entre a presente gerações em entregar um meio ambiente ecologicamente equilibrado, igual ou melhor ao que ele encontrou, à futura geração. 
Portanto, o desenvolvimento econômico não pode ser imposto a qualquer custo e provocar a degradação do meio ambiente, cujos bens são finitos e indispensáveis à sadia qualidade de vida da presente e futuras gerações. Isto sem se olvidar que a defesa do meio ambiente, entendido como valor permeado em toda a ordem constitucional, pode e deve ser utilizado como instrumento para alcançar a justiça social e a dignidade humana. Neste sentido, os ensinamentos de Eros Roberto Grau:

O princípio da defesa do meio ambiente conforma a ordem econômica (mundo do ser), informando substancialmente os princípios da garantia do desenvolvimento e do pleno emprego. Além de objetivo, em si, é instrumento necessário - e indispensável - à realização do fim dessa ordem, o de assegurar a todos existência digna. Nutre também, ademais, os ditames da justiça social. Todos têm direito ao meio ambiente ecologicamente equilibrado, bem de uso comum do povo - diz o art. 225, caput. (GRAU, 2012, p. 251)

Assim, somente é possível reconhecer que a empresa exerce suas atividades de forma socialmente responsável quando ela a desenvolve em estreito respeito à proteção ambiental, isto porque, sua atividade econômica tem como limite o direito a um meio ambiente sadio (art.170, VI, da Constituição Federal).

Ademais, diante da irrefutável constatação acerca da finitude dos recursos naturais, e da sua imprescindibilidade para a manutenção da vida na terra, cresceu sobremaneira o consumo responsável ligado a consumidores que almejam adquirir bens produzidos de forma ecologicamente correta. Neste contexto, cidadãos ativos, acionistas indignados e consumidores são responsáveis pela mudança de paradigma, e como consequência direta, alterou-se a equação de Friedman. Logo, as empresas que terão maiores chances de se desenvolver no mercado econômico não serão as ditas "narcisistas", mas as que pautam sua atividade sob o manto da responsabilidade social.

Enfim, não há que se olvidar que é através de sua conduta ética em relação à sociedade e, sobremodo ao meio ambiente, que a empresa melhora a sua imagem, beneficia a coletividade e cumpre a função social de sua atividade econômica.

\section{A responsabilidade empresarial no contexto da globalização}

A responsabilidade social e a cidadania empresarial são estratégias de posicionamento das empresas que configuram um importante diferencial competitivo para 
seus produtos e marcas em face de uma dinâmica de mercado cada vez mais globalizado e competitivo.

No atual mundo globalizado, em qualquer lugar e a qualquer momento, o cliente tem à sua disposição os produtos e serviços que deseja. Dentro dessa realidade, as empresas que conseguem se diferenciar na mídia, principalmente através de seu engajamento social, fortalece sua imagem e a de seus produtos e, consequentemente, ganha mercado, pois os consumidores atuais sabem do poder de suas escolhas e atribuem um importante valor aos produtos e serviços de empresas que apoiam as causas socioambientais, pois acreditam que ao consumi-los estarão também contribuindo para tornar o mundo melhor.

Destarte, o empresário que deseja fortalecer sua marca e apresentar seus produtos e serviços como atrativos ao mercado consumidor, precisa demonstrar para a sociedade que tem preocupações sociais e que faz investimentos tendentes a reduzir as externalidades negativas provenientes do exercício de sua atividade econômica. Por outro lado, conforme bem analisado por Robert Henry Srour (2003, p. 52), a população consumerista exerce uma forte influência no mercado e tem o poder de causar prejuízos consideráveis a um empresário socialmente irresponsável.

Nesse contexto, não há dúvidas que com o acirramento da competição empresarial no mundo globalizado, empresas que reconhecidamente investem em responsabilidade social e ambiental, são naturalmente mais atrativas ao mercado e aos consumidores.

Dito de outro modo, esse novo consumidor não deseja apenas adquirir produtos, ele quer também "consumir melhor", conforme bem salientado por Lipovetsky (2007, p. 344), razão pela qual dão especial preferência às empresas que atuam de maneira ética e incorporam em sua atividade práticas socialmente responsáveis.

Por conseguinte, resta evidenciado que a cidadania empresarial é um novo conceito decorrente de um movimento social internalizado por diversas empresas, cujo objetivo seria conferir uma imagem diferenciada aqueles empreendimentos que se converteram em tradicionais investidoras de projetos sociais.

\section{Ações de responsabilidade social aptas a atraírem benefícios fiscais}

Impossível não se falar em tributação no contexto em que se aborda a RSE, uma vez que o tributo vem demonstrando ser um importante instrumento motivador e mantenedor de 
uma conduta socialmente responsável, tanto que, em boa medida, a responsabilidade social é considerada por muitos como decorrente de incentivos e benefícios fiscais.

Logo, com o escopo de compatibilizar a atuação ética empresarial e sua finalidade lucrativa, Jussara Nasser Ferreira (2004, p. 46) propõe a busca do equilíbrio e compatibilização entre os interesses ao afirmar que "a função social da empresa delimitada pela ordem econômica constitucional e de acordo com o pensamento funcionalista passa a ser definida na perspectiva da busca de equilíbrio entre os interesses da empresa e os interesses da sociedade de consumo".

Por conseguinte, é necessário que o Estado promova condições motivadoras para que as empresas pautem sua atuação com vistas à promoção do bem-comum. E uma forma de incentivá-las a se tornarem cidadãs é justamente através de concessões de benefícios fiscais.

E no campo da tributação, essa motivação pode ser alcançada mediante a concessão de incentivos fiscais, compreendidos como estímulos concedidos pelo governo, na área físcal, às empresas que, em decorrência da sua atuação socialmente responsável, contribuam para o desenvolvimento sustentável nacional, a erradicação da pobreza e a redução das desigualdades regionais e sociais, que são os objetivos fundamentais da República.

O Estado, por meio da edição de normas jurídicas, detém o atributo da coerção, capaz de dirigir os comportamentos da sociedade. Mas além do poder de impor comportamentos, pode se utilizar de ferramentas de indução, na maioria das vezes mais eficientes que as normas de direção.

Consequentemente, através da concessão de incentivos fiscais, o Estado intervém na economia estimulando comportamentos que tenham como finalidade, objetivos previstos constitucionalmente, entre eles estimular as ações socialmente responsáveis das empresas.

Os incentivos fiscais se justificam, pois não se constituem meros privilégios, ao contrário, seria o reconhecimento por parte do Estado acerca do esforço empreendido pelo cidadão em cumprir a lei, visando assim não apenas castigar o recalcitrante, mas sobremodo tributar menos, a título de prêmio, quem realiza a atividade desejada pelo Estado.

Destarte, não há que se olvidar que diante da adoção de uma política extrafiscal, que contenha instrumentos de incentivo ao desenvolvimento de atividades, através da implementação de normas tributárias indutoras, o empresariado vislumbra uma forma de contribuir com o contexto econômico, promover o nome da empresa e ainda obter incentivos fiscais. Há, portanto, perfeita compatibilização de interesses, conjugando as necessidades da 
sociedade, do empresariado e do Estado, na medida em que ocorre a concretização das finalidades do Estado na busca da justiça social.

Como forma de incentivar o empresariado a implementar projetos de responsabilidade social, já há na legislação nacional a previsão de alguns incentivos fiscais ligados às áreas social e cultural, bem como de promoção dos direitos e garantias de crianças e adolescentes, os quais estabelecem um teto de dedução dos impostos devidos, em percentual que não afeta, significativamente, os cofres públicos.

As Leis de Incentivo permitem que as empresas fomentem projetos que reflitam postura de responsabilidade social e seus valores. É uma maneira de elas se engajarem com atividades de cunho social que, além de promoverem ações de impacto positivo na sociedade, também são vantajosas para a imagem da instituição.

Por outro lado, quando o governo compartilha com as empresas a responsabilidade de investir em ações sociais, ele aumenta o acesso da população a iniciativas que, sem o incentivo, dificilmente se concretizaria. A relação é bilateral: de um lado, instituições com recursos para serem investidos e capacidade de organizar a sua distribuição. Do outro, projetos que primam pela sustentabilidade e pela responsabilidade social recebem investimentos e contribuem também a melhoria da qualidade de vida de toda uma comunidade.

Assim, considerando a relevância da empresa no contexto socioeconômico nacional, sendo ela um eficiente agente de transformação social, conclui-se que o Estado, como forma de incentivar o empresariado a implementar projetos de responsabilidade social, além dos incentivos fiscais já previstos na legislação pátria, poderia instituir outros benefícios fiscais, vez que os tributos representam um importante aliado na consolidação e disseminação das ações de responsabilidade social pelas organizações.

\section{Considerações finais}

O artigo abordou a função social da empesa para, em momento posterior, investigar a responsabilidade social empresarial, ambos sob a égide do Estado Democrático de Direito.

A função social da empresa é um poder-dever que modifica o antigo modelo individualista, cuja única preocupação se voltada para a obtenção de lucro, surgindo um novo 
paradigma, uma nova mentalidade empresarial atenta aos interesses sociais, sobremodo a imagem que essa empresa pretende construir perante a sociedade.

A empresa, principalmente com o advento da Constituição de 1988, tem uma função social a cumprir, que decorre do princípio constitucional da função social da propriedade e da dignidade da pessoa humana, visto que a empresa é a propriedade dos bens e serviços produzidos, e deve exercer sua atividade econômica de forma ética e levando em consideração os anseios e necessidades da sociedade que a cerca.

Demonstrou-se que as ações de responsabilidade social configuram um importante diferencial competitivo para seus produtos e marcas, principalmente considerando a dinâmica de mercado cada vez mais globalizado e competitivo.

O desenvolvimento nacional tem que ser econômico, social e ambiental. E a empresa contemporânea é a instituição de destaque no século XXI. Por conseguinte, a sociedade espera que ela assuma cada vez mais uma postura ética em relação à comunidade e ao meio ambiente, além de atuar ao lado do Estado, contribuindo com o desenvolvimento da nação.

Por fim, conforme demonstrado ao longo desse estudo, dado a relevância da empresa no contexto nacional, e a inequívoca transformação que ela é capaz de operar no seio da sociedade, conclui-se que o Estado, como forma de incentivar o empresariado a implementar projetos de responsabilidade social, além dos incentivos fiscais já previstos na legislação nacional, poderia instituir outros benefícios fiscais, vez que os tributos representam um importante aliado na consolidação e disseminação das ações de RSE.

\section{REFERÊNCIAS}

BRASIL. Constituição Federal de 1988. Promulgada em 5 de outubro de 1988. Disponível em: http://www.planalto.gov.br/ccivil_03/constituicao/constituição.htm. Acesso em 30 set. 2019.

COMPARATO, Fabio Konder. Função social da propriedade dos bens de produção. Revista de Direito Mercantil, Industrial, Econômico e Financeiro, ano XXV (Nova Série), $\mathrm{n}^{\circ}$ 63, julho/setembro, p. 109-126, 1996.

DINIZ, Maria Helena. Curso de Direito Civil Brasileiro. Volume 8: Direito de Empresa. 2. ed. reformula da. São Paulo: Saraiva, 2009.

DUGUIT, Leon. Las transformaciones del derecho publico e privado. Buenos Aires: Editorial Heliasta, 1975.

ETHOS. Práticas empresariais de responsabilidade social: Relações entre os Princípios do Global Compact e os Indicadores Ethos de Responsabilidade Social. São Paulo, 2003. Disponível em: http://www.ethos.org.br. Acesso: 6 set. 2019. 
FELIX, Luiz Fernando Fortes. A Conjuntura Atual e a Responsabilidade Social e Cidadã das Empresas. São Paulo: Instituto Ethos: 2003.

FERREIRA, Jussara Suzi Assis Borges Nasser. Função Social e Função Ética da Empresa. In Argumentum - Revista de Direito da Universidade de Marília, v. 04, Marília: Unimar, p. 35-52, 2004. Disponível em: http://ojs.unimar.br/index.php/revistaargumentum/article/view/699/352. Acesso 30 set. 2019.

FRAZÃO, Ana. Função social da empresa: repercussões sobre a responsabilidade civil de controladores e administradores de S/As. Rio de Janeiro: Renovar, 2011.

FRIEDMAN, Milton. Capitalismo e liberdade. São Paulo: Abril Cultural, 1984.

GRAU, Eros Roberto. A Ordem Econômica na Constituição de 1988. 15 ed. rev. e atual. São Paulo: Malheiros, 2012.

LIPOVETSKY, Gilles. A felicidade paradoxal: Ensaio sobre a sociedade de hiperconsumo. Trad. de Maria Lucia Machado. São Paulo: Companhia das Letras, 2007.

PETTER, Lafayete Josué. Princípios Constitucionais da Ordem Econômica: o significado e o alcance do art.170 da Constituição Federal.- São Paulo: Editora Revista dos Tribunais, 2005.

SROUR, Robert Henry. Ética empresarial: a gestão da reputação. 5. reimpressão. Rio de Janeiro: Elsevier, 2003.

STARKE, Linda. As cinco etapas da evolução moral da empresa. In: RAY, Michael; RINZLER, Alan (org.). O novo paradigma nos negócios. São Paulo: Cultrix, 1999.

TENÓRIO, Fernando Guilherme. Responsabilidade social empresarial: teoria e prática. 2. ed. Rio de Janeiro: FGV, 2006.

YUNUS, Muhammad. Um mundo sem pobreza: a empresa social e o futuro do capitalismo. São Paulo: Ática, 2008. 